\title{
Samoprocjena stresa i primjena strategija suočavanja sa stresom kod studenata preddiplomskog stručnog studija Sestrinstvo
}

\section{Self evaluation of stress and apllication of coping strategies in the students of pre-graduate professional study of Nursing}

\author{
Marija Žagar', Radoslav Kosić2,3 \\ ${ }^{1}$ Studentica prve godine diplomskog sveučilišnog studija Sestrinstvo - Promicanje i zaštita mentalnog zdravlja, Viktora cara Emina 5, 51000 Rijeka, \\ Hrvatska \\ ${ }^{2}$ Klinički Bolnički centar Rijeka, Klinika za pedijatriju, Istarska 43, 51000 Rijeka, Hrvatska / University Hospital Center Rijeka, Clinic for pediatric, Istarska 43, \\ 51000 Rijeka, Croatia \\ ${ }^{3}$ Fakultet zdravstvenih studija Rijeka, Sveučilište Rijeka, Viktora cara Emina 5, 51000 Rijeka, Hrvatska / Faculty of Health Studies Rijeka, Univesity of Rijeka, \\ Viktora cara Emina 5, 51000 Rijeka, Croatia
}

\begin{abstract}
Sažetak
Uvod: Vrijeme studiranja označava veliku stepenicu prema osamostaljenju i putu odrastanja. Tijekom tog vremena studenti se suočavaju s brojnim životnim pitanjima i raznim pritiscima sa svih strana. U tom periodu postoje mnogi stresori koji djeluju na studente. Razina stresa, kao i strategije koje studenti upotrebljavaju za suočavanje sa stresom, iznimno su važni za prevenciju nastanka mnogih bolesti i poremećaja kojima je stres jedan od mogućih uzroka.
\end{abstract}

Cilj istraživanja: Cilj je ovog rada ispitati razinu stresa kod studenata prve i treće godine redovnog preddiplomskog stručnog studija Sestrinstvo u Rijeci te identificirati najčešce oblike suočavanja sa stresom kod sudionika istraživanja.

Sudionici i metode: $U$ ispitivanje su uključeni studenti sestrinstva prve i treće godine redovnog preddiplomskog stručnog studija Sestrinstvo u Rijeci. Ukupno su sudjelovala 44 sudionika. Za provođenje istraživanja koristila se anonimna online anketa. Podaci prikupljeni anketiranjem sudionika obrađeni su metodama deskriptivne i inferencijalne statistike.

Rezultati: Prema rezultatima istraživanja, sudionici prijavljuju visoku razinu stresa koja je podjednaka kod studenata prve i treće godine. Sudionici se također, bez obzira na godinu studija, podjednako koriste određenim strategijama suočavanja. Kao način rješavanja problema i suočavanja sa stresom sudionici najčešće planiraju rješavanje problema, pozitivno ga nastoje sagledati, aktivno se nose s problemom te traže instrumentalnu i emocionalnu podršku.

Zaključak: Istraživanje pokazuje da su sudionici, bez obzira na poželjne strategije suočavanja sa stresom, pod značajno visokom razinom stresa. Postojeći načini suočavanja ne pokazuju se dovoljnima za uspješno smanjenje stresa. Uzimajući u obzir spoznaju da stres negativno djeluje na razna područja funkcioniranja te da može imati značajne posljedice na fizičko i mentalno zdravlje pojedinca, ukazuje se potreba za ozbiljnijim shvaćanjem postojanja stresa kod studenata i daljnjim istraživanjima u ovom području. Pritom je primarno usmjeriti se na načine njegove prevencije.

Ključne riječi: načini suočavanja, strategije suočavanja, stres, student Kratki naslov: Stres i načini suočavanja

\begin{abstract}
Introduction: Student period in life means a big step towards independence and the path of growing up. During this time, students face many life issues and various pressures from all sides. Many stressors affect students. The level of stress, as well as the strategies that students use to cope with it, are important for the prevention of many diseases and disorders possibly caused by stress.

Research aim: This paper aims to examine the level of stress among students of the first and third years of the regular pre-graduate professional study of $\mathrm{Nu}$ rsing in Rijeka and to identify the most common forms of coping with stress in participants.
\end{abstract}

Participants and methods: Nursing students of the first and third year of the regular pre-graduated professional study of Nursing in Rijeka were included in the study. A total of 44 respondents participated. An anonymous online survey was used to conduct the research. Data collected were processed by descriptive and inferential statistics methods.

Results: According to the survey results, respondents report high levels of stress, which are equal in first- and third-year students. Respondents also, regardless of the year of study, equally use certain coping strategies. As a way of solving problems and dealing with stress, respondents most often plan to solve the problem, try to see it positively, actively deal with the problem and seek instrumental and emotional support.

Conclusion: The research shows that the respondents, regardless of the preferable strategies for coping with stress, are under significant stress. Existing coping methods are not sufficient for the successful reduction of stress. Taking into account the knowledge of how stress harms various areas of functioning, as well as how it can have significant consequences on the physical and mental health of an individual, there is a need for more serious understanding and recognition of stress in students and further research in this area. It should primarily be based on the ways of stress prevention.

Keywords: coping strategies, stress, students, ways of coping Running head: Stress and coping mechanisms 


\section{Uvod}

Jedna od danas najuvrježenijih definicija stresa podrazumijeva da je stres reakcija organizma na pojedine situacije u kojima pojedinac osjeća ugroženost za svoje psihičko ili fizičko zdravlje. Može se definirati i kao nespecifična posljedica pojačanog zahtjeva za organizam koji nadilazi njegovu adaptacijsku moć [1]. Prema duljini trajanja, stres se može podijeliti na akutni ili kronični. Reakcija na stres može biti pozitivna što vodi k prilagodbi ljudskog organizma na nove uvjete okoline i zahtjeve koji su pred njega postavljeni. Pozitivan stres, zvan eustres, omogućuje pojedincu razvoj i rast kroz adaptaciju [2]. S druge strane, negativan stres ili distres dovodi do negativnih posljedica za organizam i opće funkcioniranje pojedinca [2]. Činitelji koji prijete ravnoteži organizma i uzrokuju stres nazivaju se stresorima [1]. Samo suočavanje sa stresom podrazumijeva akciju, bilo ponašajnu ili kognitivnu, kojom se nastoji reducirati, tolerirati ili svladati sukob između pojedinca i okoline. Značajne odrednice suočavanja čine rješavanje problema i kontrola neugodnih emocija koje stres stvara [3].

Stres je, posebno u studentskom razdoblju, donekle uobičajena pojava. Međutim, konstantno visoka razina stresa koja se javlja kod studenata alarmantna je pojava [4]. Istraživanje utjecaja stresa na studente važno je u mnogim aspektima, ali dva su posebna. Prvo, većina je studenata mla$\mathrm{da}$, a utjecaj stresnih događaja na mlade može rezultirati povećanim rizikom od mentalnih i fizičkih bolesti kasnije u odrasloj dobi [5]. Nadalje, stres može smanjiti vještine učenja prijeko potrebne $u$ akademskom okruženju; smanjenje vještina učenja važan je faktor jer smanjuje resurse studenata za postizanje akademskog uspjeha [6]. Studenti sestrinstva često doživljavaju anksioznost i stres tijekom početne kliničke prakse. Stres tijekom tog razdoblja može polučiti nekoliko negativnih ishoda, poput: loših akademskih rezultata [7], povišenih razina izgaranja i smanjenog osobnog blagostanja [8]. Sve to šteti postizanju cilja osposobljavanja, a kasnije razvoju kompetencija. Stoga je važno za učitelje da budu svjesni čimbenika koji mogu dovesti do povećanja razine stresa među studentima sestrinstva i načina kojima se koriste za prevladavanje stresora [9].

Istraživanje Hudek-Knežević i sur. [10] pokazuje rezultate o visokom stupnju stresa u studenata, posebno tijekom ispitnog razdoblja, gdje dolazi i do smanjenja funkcije različitih pokazatelja staničnog imuniteta. Petek [11] je u Bjelovaru proveo istraživanje u kojemu je istražen stres kod studenata sestrinstva, a rezultati pokazuju da $51 \%$ sudionika razdoblje studiranja percipira kao vrlo stresno. Slične rezultate daje i istraživanje Backović i sur. [12] koje je provedeno na Medicinskom fakultetu u Beogradu, gdje više od $50 \%$ studenata ispite doživljava kao jako stresne.

Janušić u istraživanju koje je provela u Zagrebu na studentima Zdravstvenog veleučilišta izvještava da stres za vrijeme ispitnih rokova u značajnoj mjeri uzrokuje pojavu poteškoća štetnih za zdravlje. Kod sudionika su se javljali nemir, razdražljivost i konstantne promjene raspoloženja, a osjećaja krivnje u sudionika gotovo da i nije bilo. Također, sudionici su izvještavali o slabljenju koncentracije i usporenom tijeku misli prilikom učenja. Od tjelesnih reakcija najčešće su izvješćivali o želučanim i probavnim smetnjama [13].

Olvera Alvarez i sur. [14] ističu da su na stres posebno osjetljivi tek diplomirani studenti, odnosno studenti koji prelaze iz škole u radno okruženje. U prve je dvije godine nakon diplome $34 \%$ njih mijenjalo posao te su bili posebno osjetljivi na izgaranje čak i prije zaposlenja.

\section{Ciljevi}

\section{Cilj istraživanja je:}

ispitati razliku u razini stresa i načina suočavanja sa stresom kod studenata prve i treće godine redovnog preddiplomskog stručnog studija Sestrinstvo.

Postavljaju se sljedeće hipoteze:

H1: Studenti su pod visokom razinom stresa;

$\mathrm{H} 2$ : Studenti većinom upotrebljavaju negativne oblike suočavanja sa stresom;

H3: Studenti treće godine preddiplomskog stručnog studija sestrinstva iskazat će višu razinu stresa u odnosu na studente prve godine studija.

\section{Sudionici i metode}

\section{Sudionici}

U ispitivanje su bili uključeni studenti sestrinstva prve i treće godine redovnog preddiplomskog stručnog studija sestrinstva u Rijeci. Ukupno je sudjelovalo 44 sudionika, od toga 34 žene (77 \%) i 10 muškaraca (23\%). Od ukupnog broja sudionika, njih 30 (70 \%) nije iz Rijeke, nego studira u Rijeci, a 14 sudionika (30 \%) je iz Rijeke.

\section{Etičnost istraživanja}

Prije provođenja istraživanja dobiveno je odobrenje Etičkog povjerenstva Fakulteta zdravstvenih studija u Rijeci. Sudionici su obaviješteni da je sudjelovanje u ovom istraživanju potpuno dobrovoljno, da se mogu slobodno i bez ikakvih posljedica povući iz istraživanja u bilo kojem trenutku bez navođenja razloga te da ankete istraživanja i pitanja neće izazvati (ili imati potencijal) bilo kakve (osobne, reputacijske ili profesionalne) štete ili nelagode.

\section{Ispitni materijal i metode istraživanja}

Za provođenje istraživanja koristila se anonimna online anketa. Anketa sadržava:

Upitnik br. 1 - opći demografski podaci, sastavljen za potrebe ovog istraživanja.

Upitnik br. 2 - „Koliko ste pod stresom", originalni upitnik od 36 pitanja prilagođen studentima sestrinstva i preoblikovan uporabom dvaju upitnika: Self related 36 (SF 36) [15] te General Health Questionnaire (GHQ) [16]. Upitnik se sastoji od 36 pitanja s ponuđenim odgovorima da/ne/katkad. Svaki odgovor nosi određeni broj bodova koji se na kraju zbrajaju. Dobiveni se rezultat uspoređuje s ponuđenom originalnom ljestvicom koja pokazuje postojeću razinu stresa kod sudionika. 
Upitnik br. 3 - upitnik stilova suočavanja sa stresnim situacijama. Inačica upitnika suočavanja sa stresnim situacijama (Coping Orientation to Problems Experienced - COPE) [17] koju su Hudek-Knežević i Kardum adaptirali prema našim kulturalnim uvjetima. Sastoji se od 71 pitanja. Odgovori se boduju na ljestvici Likertova tipa od 5 stupnjeva (0 - 4), a glase: 0 - nikada se tako ne ponašam, 1 - katkada se tako ponašam, 2 - obično se tako ponašam, 3 - često se tako ponašam, 4 - uvijek se tako ponašam. Ta su pitanja pri obradi podataka grupirana u 15 podskupina kao 15 različitih oblika suočavanja sa stresnim situacijama.

Pri obradi rezultata istraživanja korištene su metode deskriptivne i inferencijalne statistike. Razina statističke značajnosti postavljena je na $\mathrm{p}<0,05$.

\section{Rezultati}

U istraživanju je sudjelovalo 44 sudionika od čega su 34 žene, a 10 muškaraca. Prosječna dob sudionika iznosi $M_{\text {dob }}=$ 21,55 godina ( $s d=2,18$ godina). $S$ obzirom na godinu studija, 18 sudionika su studenti prve godine redovnog preddiplomskog stručnog studija sestrinstva, dok 26 sudionika pohađa treću godinu navedenog studija.

Ukupna količina stresa mjerena je kao zbroj odgovora na pitanja o stresnim situacijama. Sudionici prijavljuju prosječno $24,68(s d=7,99)$ stresa mjereno na skali 0 - 72, što prema rezultatima označava visoku razinu stresa.

Slika br. 1 prikazuje zbroj bodova upitnika „Koliko ste pod stresom" kod pojedinog sudionika. Skala zbroja bodova govori sljedeće: od 1 do 6 bodova - „Doista ste otporni na stres.", od 7 do 13 bodova - „Imate nekih problema, ali ste izvan kritičnog područja.", od 14 do 20 bodova - „Stres vas nagriza, poradite na povećanju svojih sposobnosti svladavanja stresa.", od 21 do 30 bodova - „Vi ste pod izraženim stresom, posavjetujte se sa svojim liječnikom i potražite anti-stres program!“, 31 i više bodova - „Mijenjajte stil života!“. Iz prikazanog grafikona vidljivo je da je zbroj čestica većine sudionika iznad 20, što govori da su pod visokom razinom stresa.

U tablici 1. prikazana je serija t-testova koja je pokazala da sudionici, bez obzira na godinu studija, osjećaju podjednaku količinu stresa te da je učestalost različitih načina nošenja sa stresom podjednaka bez obzira na godinu studija.

TABLICA [1] Razlike u količini stresa i načinima nošenja sa stresom s obzirom na godinu studija

\begin{tabular}{|c|c|c|c|c|}
\hline & 1. godina & 3. godina & $\mathrm{t}$ & $\mathrm{p}$ \\
\hline $\begin{array}{l}\text { Pozitivno sagledavanje } \\
\text { problema }\end{array}$ & 2,54 & 2,72 & $-0,76$ & $>0,05$ \\
\hline $\begin{array}{l}\text { Mentalno odvajanje } \\
\text { od problema }\end{array}$ & 1,67 & 1,94 & $-1,21$ & $>0,05$ \\
\hline $\begin{array}{l}\text { Izbacivanje negativnih } \\
\text { emocija }\end{array}$ & 1,37 & 1,78 & $-1,46$ & $>0,05$ \\
\hline $\begin{array}{l}\text { Instrumentalna } \\
\text { podrška }\end{array}$ & 2,57 & 2,63 & $-0,20$ & $>0,05$ \\
\hline $\begin{array}{l}\text { Aktivno nošenje sa } \\
\text { stresom }\end{array}$ & 2,42 & 2,71 & $-1,28$ & $>0,05$ \\
\hline Poricanje & 0,64 & 0,68 & $-0,24$ & $>0,05$ \\
\hline Okretanje religiji & 1,47 & 1,59 & $-0,30$ & $>0,05$ \\
\hline Humor & 1,69 & 1,94 & $-0,90$ & $>0,05$ \\
\hline $\begin{array}{l}\text { Ponašajno odvajanje } \\
\text { od problema }\end{array}$ & 0,81 & 0,77 & 0,18 & $>0,05$ \\
\hline Suzdržavanje & 2,07 & 1,97 & 0,47 & $>0,05$ \\
\hline $\begin{array}{l}\text { Traženje emocionalne } \\
\text { podrške }\end{array}$ & 2,21 & 2,42 & $-0,70$ & $>0,05$ \\
\hline Alkohol & 0,26 & 0,58 & $-1,35$ & $>0,05$ \\
\hline Prihvaćanje problema & 2,33 & 2,58 & $-1,05$ & $>0,05$ \\
\hline $\begin{array}{l}\text { Supresija } \\
\text { kompetitivnih } \\
\text { aktivnosti }\end{array}$ & 2,03 & 2,05 & $-0,09$ & $>0,05$ \\
\hline $\begin{array}{l}\text { Planiranje rješavanja } \\
\text { problema }\end{array}$ & 2,85 & 3,00 & $-0,66$ & $>0,05$ \\
\hline Količina stresa & 24,89 & 24,54 & 0,14 & $>0,05$ \\
\hline
\end{tabular}




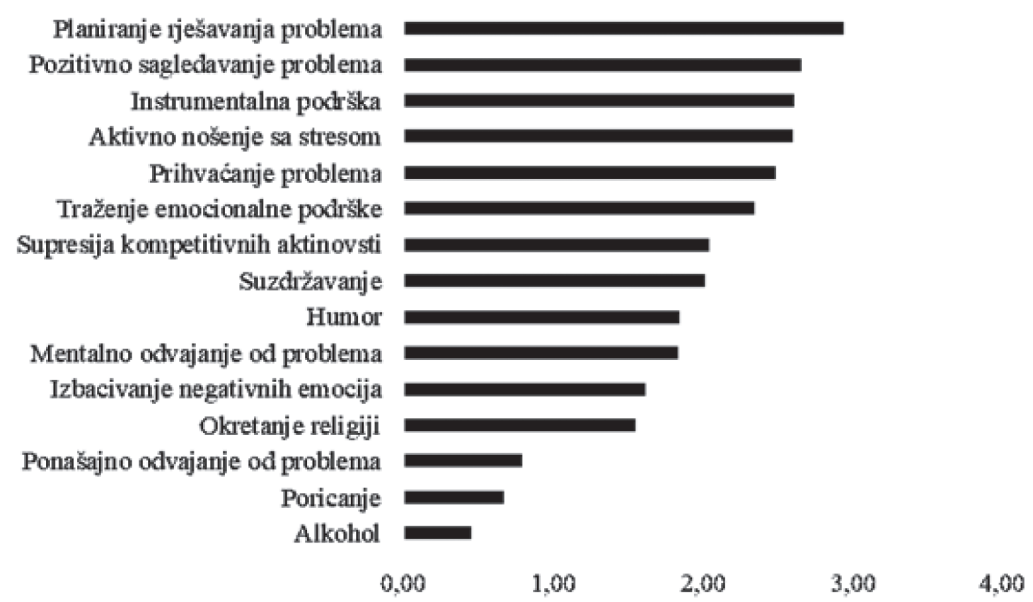

SLIKA [2] Učestalost načina nošenja sa stresom

Slika 2. prikazuje analizu provedenu na cjelokupnom uzorku, bez podjela na godinu studija. Po učestalosti, sudionici najčešće planiraju rješavanje problema, pozitivno ga nastoje sagledati, aktivno se nose s problemom te traže instrumentalnu i emocionalnu podršku. Korištenje alkohola kao načina prevladavanja stresa, poricanje problema i ponašajno odvajanje od problema oblici su suočavanja koji su najmanje zastupljeni u obje skupine.

U tablici 2. prikazana je povezanost određenih načina suočavanja sa stresom i ukupne količine stresa koja je testirana Pearsonovim koeficijentom korelacije. Ukupna količina stresa značajno je pozitivno povezana s Ponašajnim odvajanjem od problema $(r=0,57)$ i Okretanju alkoholu $(r=0,49)$. Aktivno nošenje sa stresom ( $r=-0,35)$ te Suzdržavanje ( $r=$ $-0,32$ ) negativno je povezano s ukupnom količinom stresa. Drugim riječima, sudionici koji se češće suzdržavaju i koji se aktivno nose s problemom prijavljuju niže količine stresa. Neki od načina suočavanja sa stresom često se koriste usporedno pa su najviše korelacije opažene za sljedeće kategorije: Prihvaćanje problema i Planiranje rješavanja problema $(r=0,72)$, Planiranje rješavanja problema i Pozitivnog sagledavanja problema $(r=0,77)$ te za Planiranje rješavanja problema i Aktivnog nošenja sa stresom $(r=0,81)$.

TABLıCA [2] Povezanost različitih načina nošenja sa stresom i ukupnom količinom stresa

\begin{tabular}{|c|c|c|c|c|c|c|c|c|c|c|c|c|c|c|c|}
\hline & $\begin{array}{c}\text { Pozitivno } \\
\text { agledavanje } \\
\text { problea }\end{array}$ & $\begin{array}{c}\text { Mentalino } \\
\text { odvajenje oo } \\
\text { problema }\end{array}$ & $\begin{array}{l}\text { Iztbacivanje } \\
\text { asgatimnih } \\
\text { eocija }\end{array}$ & $\begin{array}{l}\text { Inutrumentaln } \\
\text { a podrika }\end{array}$ & $\begin{array}{c}\text { Aktivno } \\
\text { solenja sa } \\
\text { struos }\end{array}$ & Potianj & $\begin{array}{l}\text { Okreanj } \\
\text { e traligiji }\end{array}$ & Huenor & $\begin{array}{c}\text { Ponaiajno } \\
\text { ofvajaje of } \\
\text { peoblea }\end{array}$ & $\begin{array}{c}\text { Suzdravanj } \\
\text { e }\end{array}$ & $\begin{array}{c}\text { Traienja } \\
\text { eccionalata } \\
\text { podrike }\end{array}$ & $\begin{array}{c}\text { Altoho } \\
1\end{array}$ & $\begin{array}{l}\text { Pribrucarje } \\
\text { problesa }\end{array}$ & $\begin{array}{l}\text { Supesesija } \\
\text { kompatitimi } \\
\text { a ditinoruti }\end{array}$ & $\begin{array}{l}\text { Planinajja } \\
\text { fjeisvanja } \\
\text { problea }\end{array}$ \\
\hline $\begin{array}{c}\text { Man aino ofrajanje of } \\
\text { probleas }\end{array}$ & 0,15 & & & & & & & & & & & & & & \\
\hline $\begin{array}{l}\text { Irbacivanje negati vilh } \\
\qquad \text { amoxija }\end{array}$ & 0.28 & 0.07 & & & & & & & & & & & & & \\
\hline Iestrusentaha podrika & 0.23 & 0,16 & sqo* & & & & & & & & & & & & \\
\hline Átivno no hanja a strosom &,$n^{* *}$ & 0.17 & 0.18 & 0.25 & & & & & & & & & & & \\
\hline Poricanje & -0.28 & $34^{*}$ & 0.11 & $-0,03$ & -0.22 & & & & & & & & & & \\
\hline Ołretanje religiji & 0,08 & 0,17 & $31^{*}$ & 0,12 & 0.00 & 0,16 & & & & & & & & & \\
\hline Husor &, $47^{* *}$ & $49 * *$ & -0.01 & 0.01 & 0.27 & -0.04 & $-0,09$ & & & & & & & & \\
\hline $\begin{array}{c}\text { Ponaỉjno od vajanje od } \\
\text { problasa }\end{array}$ & -0.23 & 0.12 & 0,13 & 0.06 & $.309 *$ &, $62 *$ & 0.11 & -0.15 & & & & & & & \\
\hline Suzdriavanje &, $501^{* *}$ & 0.00 & -0.16 & $-0,03$ &, $43^{* *}$ & $-0,22$ & $-0,15$ & 0.20 & -0.17 & & & & & & \\
\hline $\begin{array}{l}\text { Trabenje enocionalste } \\
\text { podrike }\end{array}$ & 0.29 & 0.16 & $.60 * *$ &, $77 *$ & $336^{*}$ & 0.02 & 0.29 & $-0,04$ & 0.05 & $-0,05$ & & & & & \\
\hline Atkohol & $-0,11$ & 0,00 & 0.04 & -0.24 & $-0,02$ & 0,24 & 0.18 & 0.01 &, $31^{*}$ & $-32^{*}$ & $-0,15$ & & & & \\
\hline Prihvocanje probleas &, $58+*$ & $30^{*}$ & 0,17 & 0.23 &, $59 * *$ & 0,02 & 0.02 & $39 * *$ & $-0,02$ & 0.29 & 0.28 & $-0,06$ & & & \\
\hline $\begin{array}{l}\text { Supresija koompetitiveilh } \\
\text { akktinovsti }\end{array}$ &, $45^{* *}$ & 0.21 & -0.06 & 0.07 &, $44 * *$ & 0.13 & 0.15 & 0.19 & 0.07 &, $32^{*}$ & 0.25 & $-0,11$ & , 44** & & \\
\hline $\begin{array}{l}\text { Planiranja fjeisvanja } \\
\text { probleat }\end{array}$ &, $77 *$ & 0.21 & 0.11 & 0.23 & $s 1^{* *}$ & $-0,19$ & 0.06 & 0,24 & $-0,22$ &, $5 \mathrm{~s}^{+*}$ & $32^{*}$ & $-0,17$ &, $72 * *$ &, $55 * *$ & \\
\hline Koticina uttous & -0.30 & -0.06 & -0.07 & -0.27 & $-0,35^{*}$ & 0.30 & 0.25 & -0.24 &, $57 *$ & $-32^{*}$ & -0.15 & , 4 (9** & -0.22 & $-0,03$ & $-34^{*}$ \\
\hline
\end{tabular}




\section{Rasprava}

Provedeno istraživanje temelji se na količini stresa i najčešćim oblicima suočavanja sa stresom kod studenata prve i treće godine redovnog preddiplomskog stručnog studija sestrinstva u Rijeci.

Istraživanje provedeno u Dubrovniku na studentima prve i treće godine redovnog i izvanrednog studija sestrinstva pokazuje slične, ravnomjerne rezultate pri raspodjeli stresa s obzirom na godinu studija. Navedeno istraživanje također, prema zbirnim bodovima, ukazuje na postojanje visokog stupnja stresa kod sudionika [1].

Rezultati istraživanja koje je provela Kalebić Maglica [18] ukazuju da je izbjegavanje kao oblik suočavanja sa stresom povezanim sa školskim aktivnostima kratkoročno djelotvorna strategija jer pomaže adaptaciji i povećava pozitivno raspoloženje nakon izlaganja stresoru. Taj se nalaz ne podudara s istraživanjem koje su proveli Labrague i sur. [5] čiji rezultati ukazuju na to da izbjegavanje negativno utječe na pojedinca i njegovo raspoloženje. Izbjegavanje, odnosno odvajanje od problema, bilo ponašajno ili mentalno, prema provedenom je istraživanju manje zastupljeno. Moglo bi se reći da izbjegavanje suočavanja s problemom trenutno može pomoći pojedincu da kratkoročno odvrati pažnju od problema te sagleda situaciju iz druge perspektive. No, to bi bilo djelotvorno samo u nekim manje važnim životnim situacijama i pri manjim stresorima [7]. U konačnici, ovaj način suočavanja ne smatra se pozitivnim za pojedinca jer on svojim ignoriranjem problema, maštanjem o drugim stvarima i slično zapravo ne rješava postojeći problem koji se time vjerojatno neće ukloniti ili će se još i pogoršati [9]. Aspinwall i Taylor [19] tvrde da kronična, dugotrajna uporaba takvog načina suočavanja predstavlja psihološki rizičan faktor koji može doprinijeti razvoju raznih negativnih simptoma.

Traženje emocionalne podrške u provedenom je istraživanju način suočavanja sa stresom kojim se sudionici često koriste. Studenti kao način suočavanja prakticiraju razgovor s nekom osobom o svojim osjećajima, traže podršku od prijatelja i rodbine, teže za suosjećanjem i razumijevanjem. Potreba za potporom i traženje podrške, pa i savjeta od drugoga, može doprinijeti boljem psihofizičkom funkcioniranju pojedinca, kao i nošenju sa stresorima. O tome govore neka istraživanja u kojima autori navode da osobe u stresnim situacijama žele biti u društvu drugih ljudi zato što to smanjuje njihovo negativno emocionalno stanje [7, $8,18]$. Rafati i sur. [9] u svojem istraživanju ističu da izražavanje emocija smanjuje stres i povećava osjećaj dobrobiti kod pojedinca. S druge strane, ovaj način suočavanja može djelovati i suprotno ako okolina nepovoljno reagira na pojedinčevo izražavanje emocija i ne pokaže adekvatnu potrebnu podršku. Time može uzrokovati dodatnu tjeskobu te povećati razinu stresa i nesigurnost $[7,8]$. Može se zaključiti da je za pozitivan način suočavanja sa stresnim situacijama potrebno da pojedinac u svojoj okolini ima osobe koje će mu pružiti potrebnu emocionalnu podršku.

Načini suočavanja sa stresom koji su najčešće prisutni kod sudionika provedenog istraživanja ukazuju na zrelo promišljanje i donošenje odluka bez obzira na godinu studija.
Ovo su, neupitno, pozitivni načini suočavanja. Pojedinac je svjestan postojanja stresa te teži pronalaženju uzroka stresora, planira i traži najbolji način suočavanja s istim. Kada je potrebno, traži od drugoga savjet i razgovara o svojim mogućnostima. Pri suočavanju sa situacijom koju ne zna riješiti, obraća se za pomoć osobama koje imaju slična iskustva. Na taj način pojedinac ne brza s odlukama, ne upušta se u trenutno, impulzivno, najčešće nezdravo i neefektivno rješavanje problema. Sagledava problem s različitih aspekata i teži najboljem načinu njegova uklanjanja te postepeno kreće u suočavanje $s$ istim. Pokušava problem sagledati s pozitivnog stajališta. Ako se problem ne može riješiti, ovaj pristup problemu pojedincu omogućuje dovoljno vremena da se s njime suoči i kao takvog ga prihvati. Između ostalog, postojeći će problem u tom slučaju pojedinac nastojati iskoristiti kao vrijedno životno iskustvo.

U provedenom istraživanju prikazana je i međusobna povezanost različitih načina suočavanja sa stresom, kao i s ukupnom količinom stresa. Tako je, primjerice, aktivno nošenje sa stresom značajno pozitivno povezano s pozitivnim sagledavanjem problema. Osobe koje se suzdržavaju također pozitivno sagledavaju problem i aktivno se nose sa stresom. Pojedinci koji traže emocionalnu podršku često istodobno traže instrumentalnu podršku te izbacuju negativne emocije. Slične rezultate dobili su i neki drugi autori u svojim istraživanjima [5, 6, 7]. S druge strane, od povezanosti koje vode ka negativnom suočavanju sa stresom mogla bi se istaknuti uska povezanost poricanja i mentalnog odvajanja od problema, kao i ponašajnog odvajanja od problema i poricanja. Isto tako, postoji povezanost konzumacije alkohola s humorom i suzdržavanjem. Prema ovim se podacima može zaključiti da mentalno odvajanje od problema u manjoj mjeri može biti korisno ako je povezano $s$ nekim od pozitivnih načina suočavanja. No, isto tako može voditi u suprotnom smjeru neučinkovitog suočavanja ako je povezano s nekim od negativnih načina suočavanja kao što je poricanje postojanja problema. Poricanje postojanja problema vodi k njegovom zanemarivanju i ponašajnom odvajanju od istog, što predstavlja neučinkovito suočavanje [9]. Takvim pristupom, dokle god pojedinac ne poduzima ništa vezano za problem, on najvjerojatnije neće nestati, nego se može pogoršati i manifestirati u obliku nekog mentalnog poremećaja. Suzdržavanje od priznavanja problema uz konzumaciju alkohola kao načina nošenja sa stresom još je jedan od načina koji ukazuje na nezrelo, neučinkovito suočavanje $[7,8,9]$.

Što se same količine stresa tiče, u provedenom istraživanju ona je negativno usko povezana s aktivnim nošenjem sa stresom, suzdržavanjem i planiranjem rješavanja problema. Ti podaci ukazuju na pad količine stresa pri navedenim načinima suočavanja. Bržom osviještenosti i prihvaćanju problema te pronalaženju načina njegova rješavanja, razina se stresa kod pojedinca smanjuje. S druge strane, razina stresa značajno je pozitivno povezana s ponašajnim odvajanjem od problema i konzumacijom alkohola. Drugim riječima, korištenjem navedenih načina suočavanja povećava se i količina stresa. To implicira na neadekvatnost tih načina suočavanja. Ne samo da se tako problem neće riješiti nego će i razina stresa rasti, što uz samu konzumaciju alkohola može dovesti do brojnih drugih negativnih stanja i poteškoća. 


\section{Zaključak}

Provedenim istraživanjem potvrđena je postavljena hipoteza da su studenti pod visokom razinom stresa. Odbacuje se postavljena hipoteza da se studenti u većem postotku koriste negativnim načinima suočavanja. Naprotiv, dokazano je da se studenti koriste strategijama suočavanja koje su opisane kao poželjne i efikasne. Također se odbacuje hipoteza da su studenti treće godine pod većom razinom stresa u odnosu na studente prve godine studija jer provedeno istraživanje pokazuje da su studenti bez obzira na godinu studija pod jednakom količinom stresa.

Zabrinjavajuće je da su studenti, bez obzira na poželjne strategije suočavanja sa stresom, pod značajno visokom razinom stresa. Postojeći načini suočavanja ne pokazuju se dovoljnima za uspješno smanjenje količine stresa. Može se zaključiti da su studenti pod stalnom većom razinom stre-

\section{Literatura/References}

[1] Cetinić I, Validžić A, Tomić M, Gavranić D, Hudorović N, 2014. The degree of stress amongst nursing students - University of Dubrovnik. SG/NJ. 2014; 19 (1): 22-5 doi.org/10.11608/sgnj.2014.19.006

[2] Karačić D, Sindik J, Raguž V, Klokoč P, Milovčević V, Burum M, 2012. Odnos zadovoljstva životom i psihološke dobrobiti sa stresom i mentalnom čvrstoćom kod studenata sestrinstva. Hrvatski časopis za javno zdravstvo 8. 2012; 29: 35-48. CROSBI ID: 573399

[3] Lacković-Grgin K. Stres u djece i adolescenata: Izvori, posrednici i učinci. Jastrebarsko: Naklada Slap; 2000.

[4] Jović K. 2015. Problemi mentalnog zdravlja kod studenata. Sveučilište u Osijeku. Završni rad.

[5] Labraque LJ, McEnroe-Petitte DM, Papathanasiou IV, et al. 2018. A cross-country comparative study on stress and quality of life in nursing students. Perspect Psychiatr Care. 2018; 54 (4):469-76. doi: 10.1111/ppc.12248.

[6] Labrague LJ, Mc Enroe-Petitte DM, Papathanasiou IV, Edet OB, Arulappan J.2015. Impact of Instructors' on Students' Perceptions of Their Own Caring Behaviors. J Nurs Scholarsh. 2015; 47 (4): 338-46. doi: 10.1111/jnu.12139.

[7] Labrague LJ, McEnroe-Petitte DM, Papathanasiou IV et al. 2018. Stress and coping strategies among nursing students: an international study. J Ment Health; 2018; 27 (5): 402-8. doi: 10.1080/09638237.2017.1417552

[8] El-Nehrawaya SM, El-Menem SA. 2018. Efficacy of Stress Management Program on the level of perceived stress and Coping Strategies among Baccalaureate Nursing Students. TSNJ. 2018; 14 (1): 56-74. doi: 10.21608/TSNJ.2018.71031

[9] Rafati F, Nouhi E, Sabzevari S, Dehghan-Nayeri N. 2017. Coping strategies of nursing students for dealing with stress in clinical setting: A qualitative study. Electron Physician. 2017; 9 (12): 6120-8. doi: $10.19082 / 6120$ sa, odnosno da su stresori koji uzrokuju stres konstantno prisutni. Shodno navedenom, bez obzira na sve napore koje studenti ulažu u suočavanje sa stresom, to je jednostavno nemoguće postići. Ovo istraživanje provedeno je na dvije relativno male skupine sudionika, u danom trenutku, što daje samo uvid u trenutno stanje i može nepovoljno utjecati na reprezentativnost uzorka te smanjiti mogućnost generalizacije rezultata. No, ipak pokazuje da stres može imati ozbiljne posljedice na fizičko i mentalno zdravje pojedinca te ukazuje na potrebu za ozbiljnijim shvaćanjem postojanja stresa kod studenata sestrinstva i daljnjim istraživanjima u ovom području pritom se usmjeravajući na načine njegove prevencije.

\section{Nema sukoba interesa}

\section{Authors declare no conflict of interest}

[10] Hudek-Knežević J, Kardum I, Lesić R. Efekti percipiranog stresa i stilova suočavanja na tjelesne simptome. Društvena istraživanja, 1998; 4 (42): 543-61.

[11] Petek K. 2016. Studiranje kao izvor stresa u životu redovnih i izvanrednih studenata Stručnog studija sestrinstva. Visoka tehnička škola u Bjelovaru. Završni rad.

[12] Backović DV, Ilić Živojinović J, Maksimović J, Maksimović M. 2012. Gender differences in academic stress and bournout among medical students in final years of education. Psychiatria Danubina. 2012; 24 (2): 175-81.

[13] Janušić P. 2018. Izvori stresa kod studenata. Sveučilište u Zagrebu Diplomski rad.

[14] Olvera Alvarez HA, Provencio-Vasquez E, Slavich GM et al.2019. Stress and Health in Nursing Students. Nursing Research. 2019; 68 (6): $453-$ 63. doi: $10.1097 /$ NNR.0000000000000383

[15] Optum.SF-36 health survey. Dostupno na: http://www.webcitation. org/6cfdiZOJl; Pristupljeno: 10. 11. 2020.

[16] Goldberg DP, Hillier VF. 1979. A scaled version of the general health questionnaire. Psychol Med. 1979; 9 (1): 139-45.

[17] Hudek-Knežević J, Kardum I. Upitnik dispozicijskog i situacijskog suočavanja sa stresom i njegove psihometrijske značajke. Godišnjak Zavoda za psihologiju. 1993; 2: 43-63.

[18] Kalebić Maglica B. 2007. Uloga izražavanja emocija i suočavanja sa stresom vezanim uz školu u percepciji raspoloženja i tjelesnih simptoma adolescenata. Psihologijske teme 16. 2007; 1:1-26. UDK 159.942.072-053.6

[19] Aspinwall LG, Taylor SE. 1992. Modeling cognitive adaptation: A longitudinal investigation of the impact of individual differences and coping on college adjustment and preformance. J Pers Soc Psychol. 1992; 63: 989-1003. 